Fanum

Sociológico

\section{Forum Sociológico}

Série II

17 | 2007

Envelhecimento activo. Um novo paradigma

\title{
Centa. Na periferia da periferia : avaliação de um projecto de ducação artística em contexto escolar
}

Daniela Mourão Craveiro e João Teixeira Lopes

\section{(2) OpenEdition}

\section{Journals}

\section{Edição electrónica}

URL: https://journals.openedition.org/sociologico/1692

DOI: 10.4000/sociologico.1692

ISSN: 2182-7427

\section{Editora}

CICS.NOVA - Centro Interdisciplinar de Ciências Sociais da Universidade Nova de Lisboa

Edição impressa

Data de publição: 1 janeiro 2007

Paginação: 139-154

ISSN: 0872-8380

\section{Refêrencia eletrónica}

Daniela Mourão Craveiro e João Teixeira Lopes, «Centa. Na periferia da periferia : avaliação de um projecto de ducação artística em contexto escolar», Forum Sociológico [Online], 17 | 2007, posto online no dia 01 janeiro 2007, consultado o 29 março 2022. URL: http://journals.openedition.org/

sociologico/1692 ; DOI: https://doi.org/10.4000/sociologico.1692 


\title{
CENTA. NA PERIFERI A DA PERIFERI A: AVALI AÇÃO DE UM PROJECTO DE EDUCAÇÃO ARTÍSTICA EM CONTEXTO ESCOLAR
}

\author{
Daniela Mourão Craveiro \\ Psicóloga Social, Instituto de Sociologia da Faculdade de Letras da Universidade do Porto \\ (daniela.craveiro@gmail.com) \\ João Teixeira Lopes \\ Sociólogo, Instituto de Sociologia da Faculdade de Letras da Universidade do Porto (jmteixeiralopes@mail.telepac.pt)
}

\begin{abstract}
Resumo
O Projecto de Formação Artística Contínua (PFAC) é um programa de intervenção educativa da autoria do CENTA (Centro de Estudos de Novas Tendências Artísticas) que visa constituir-se como factor de sucesso das aprendizagens escolares dos alunos do primeiro ciclo, bem como elemento de promoção de uma Educação Artística de qualidade. No ano lectivo de 2006/07 o Instituto de Sociologia foi responsável pela avaliação do projecto, que decorria em todas as escolas do primeiro ciclo do ensino básico do concelho de Vila Velha de Ródão. Deste trabalho surgiu um documento sedimentado numa escuta plural mediatizada pelo ecletismo do aparelho metodológico aplicado, cuja síntese agora apresentamos. Procurou-se abordar o projecto em profundidade, sistematizando os objectivos planificados, as actividades concretizadas e os efeitos educativos, de acordo com a lógica da investigação - acção e segundo o método de referenciação de Figari (1994).
\end{abstract}

Palavras-Chave: PFAC; Educação Artística; Avaliação; Investigação-Acção; Método de referenciação.

\begin{abstract}
The PFAC (Projecto de Formação Artística Contínua) is an educational intervention program created by CENTA (Centro de Estudos de Novas Tendências Artísticas). The project aims to contribute to the educational success of first grade students, as well as to promote quality in Artistic Education. In the school year of 2006/07, the IS (Institute of Sociology) was responsible for the project evaluation that was developed in all first grade schools of Vila Velha de Ródão. From this work, it was created a document based on a plural listening and an application of a rigorous methodological device, which is synthesized in the present article. It was our aim to conduct an intensive analysis of the project, to that we could systemize the designed objectives, the materialized activities and the educative effects, in accordance with the logic of the action-research and to the method of referencing of Figari (1994).
\end{abstract}

Keywords: PFAC; Artistic Education; Evaluation; Research-action; Figari's Method.

\section{Considerações Iniciais}

O Projecto de Formação Artística Contínua (PFAC) consiste numa intervenção educativa da autoria do Centro de Estudos de Novas Tendências Artísticas (CENTA). No âmbito deste projecto, profissionais especializados abordam os processos da arte contemporânea nas áreas da Dança e das Artes Plásticas de forma a estimular a criatividade e a facilitar a aprendizagem de conteúdos curriculares nos alunos do primeiro ciclo do ensino básico do concelho de Vila Velha de Ródão.

A dimensão territorial do PFAC e a sua complexidade estrutural foram as dimensões mais importantes para despoletar o interesse do Instituto de Sociologia em realizar um estudo avaliativo sobre o projecto. O investimento desta estrutura resultou na concretização de um plano de actividades que 
permitiram reunir toda uma constelação de informações pertinentes sobre o projecto educativo em discussão, mediante as diversas fontes de informação disponíveis e segundo os procedimentos metodológicos utilizados nas ciências sociais.

Através da colaboração com os diferentes agentes do projecto educativo acedeu-se a um entendimento denso sobre as motivações que induziram a criação do dispositivo educativo, as metas que foram estabelecidas, o modo como as actividades decorreram e como foram percepcionadas pelos alunos, professores titulares, formadores do projecto, direcção das entidades envolvidas e representantes de entidades locais.

Pretende-se, ainda, discutir a avaliação de projectos enquanto uma forma de investigação social aplicada, encaminhada para identificar de maneira válida e fiável variáveis-alteráveis. O conhecimento reunido e integrado através deste tipo de pesquisa é disponibilizado de modo a consistir numa ferramenta para tomada de decisões futuras na gestão do projecto e na implantação e monitorização de práticas em Educação Artística no contexto escolar.

\section{Motivações mobilizadoras}

O Instituto de Sociologia é uma unidade de investigação que procura contribuir para diversos campos de análise sociológica segundo determinadas temáticas orientadoras. Nas suas acções, promove a investigação fundamental e assegura a prestação de serviços de interesse social, procurando criar dinâmicas de envolvimento com a população, através da divulgação pública dos resultados das suas pesquisas e da plurifacetada abordagem sociológica da realidade. Nesse sentido são desenvolvidos vários projectos de diagnóstico e de monitorização de políticas, instituições, práticas e processos de mudança social com possível impacto no encadeamento social e territorial local. A avaliação do PFAC enquadra-se perfeitamente neste ponto. Contudo, surgiu de circunstâncias particulares que importa referir.

Pela primeira vez na sua história, o Instituto de Sociologia dirigiu-se a uma entidade externa com o intuito de apresentar uma proposta para a prestação de um serviço. De notar que, normalmente, este tipo de relação surge de um movimento inverso, ou seja, são as entidades que se dirigem ao instituto. Esta dinâmica invulgar foi motivada, essencialmente, pelo modo como as características definidoras do projecto respondem às temáticas que o Instituto de Sociologia se propõe trabalhar, bem como pela circunstância de tais características se adequarem às possibilidades da Investigação - Acção.

As metodologias de Investigação - Acção permitem uma relação próxima e interactiva entre o investigador e o objecto de análise. Esta abordagem metodológica, que recusa manter a tradicional dis- tância entre investigador e sujeitos, revela-se assaz pertinente em contextos educativos, na medida em que, normalmente as questões que se colocam, a este nível, não aspiram tanto a conhecimentos teóricos generalizáveis, mas sim a conhecimentos práticos, pertinentes e aplicáveis a um contexto específico (Bogdan e Bilken, 1994).

A Investigação - Acção baseia-se numa experiência construtiva, integrando os diferentes discursos sobre o tema em análise, onde os próprios sujeitos - alvo assumem a "responsabilidade de decidir quais as mudanças necessárias", sendo que "as suas interpretações e análises críticas são usadas como uma base para monitorizar, avaliar e decidir qual o próximo passo a dar no processo de investigação." (Ainscow, 2000, citado pelo Instituto de Inovação Curricular). Esta postura metodológica implica a colaboração entre os investigadores e os sujeitos em análise e desenvolve-se mediante movimentos cíclicos de acção e reflexão, o que quer dizer que, ao longo do processo de investigação, as considerações iniciais geram possibilidades de acção, que são alvo de avaliação e interpretação sistemáticas (Bogdan e Bilken, 1994).

A avaliação de um projecto como o PFAC, pela sua dimensão e natureza interdisciplinares, revela-se um palco ideal para a abordagem interactiva que advoga o movimento da investigação qualitativa (onde se pode inserir a Investigação - Acção), sem deixar de lado a aplicação de certos procedimentos quantitativos. A necessidade de adaptação sistemática de um projecto de investigação, onde a averiguação dos pontos de interesse são de difícil verificação, onde concorrem discursos com origem institucional diferente, onde se impõe uma necessidade de reformulação contínua do próprio projecto em análise, algo presente, afinal, em todos os projectos educativos (e principalmente pertinente na presença de uma parceria...), consiste, pois, num desafio a que estas metodologias qualitativas dão resposta, pela sua flexibilidade e pelas novas possibilidades que oferecem.

Neste âmbito, a evolução do próprio processo de avaliação é valorizada. Mediante a permeabilidade com o contexto e a construção de uma perspectiva plural e global sobre o projecto, confere-se à investigação social um papel mais presente e pertinente nos cenários reais sobre os quais incide, facultando a informação necessária para futuras intervenções, através de um modelo empírica e teoricamente validado.

\section{Considerações metodológicas}

Orientação teórico - metodológica

A avaliação de projectos é concebida enquanto uma forma de investigação social aplicada, conduzida 
de forma rigorosa, com o objectivo de identificar dados e informações pertinentes para apoiar um juízo sobre determinado programa. Para realizar a actividade a que nos propusemos, escolhemos enveredar pela investigação qualitativa (onde podemos inserir a Investigação - Acção), numa abordagem próxima e interactiva e em pleno contacto com o ambiente natural do projecto, orientados pelo método de referencialização de Figari (1996).

A referencialização advoga a construção de um quadro analítico que retenha o conjunto de aspectos necessários para caracterizar o projecto educativo. Assume a complexidade e contextualidade dos projectos educativos, implicando a selecção de indicadores considerados fundamentais para o projecto em questão. Segundo o seu autor, para chegar à definição de um quadro organizador e explicativo dos dados (referencial) é necessário considerar três dimensões indissociáveis e interactivas: o Induzido, o Construído e o Produzido. Assim sendo, num primeiro momento, exige-se a delimitação e caracterização do contexto de onde surge o projecto, determinando as suas motivações e averiguando a sua utilidade social (Induzido). De seguida, realiza-se a extrapolação de indicadores que caracterizem o projecto, no domínio ideal e real (Construído). E, por fim, torna-se necessário estabelecer uma ligação entre o abstracto e o concreto, avaliando os efeitos do dispositivo educativo, com base nos indicadores seleccionados (Produzido). Neste trajecto, o referencial vai sendo construído, integrando e acomodando as informações que vão surgindo. No seu final, integra o esquema das dimensões do projecto educativo, as hipóteses que reportam a cada uma delas, o seu fundamento teórico e científico, as fontes de informação de onde se recolhem estas evidências, os métodos de tratamento de dados aplicados e os critérios de avaliação de resultados (Figari, 1996; Vilhena, 2000).

De acordo com este método, foi construído um plano de avaliação que visava reunir as informações mais pertinentes sobre o projecto educativo em discussão, mediante as diversas fontes de informação disponíveis e segundo os procedimentos metodológicos utilizados nas ciências sociais.

\section{Descrição metodológica}

A partir da análise de documentos oficias sobre o PFAC e de entrevistas exploratórias com a equipa do CENTA, tivemos acesso à forma idealizada do projecto. Num primeiro momento, procurámos identificar as motivações que lhe estão implícitas e interpretá-las à luz de algumas noções de Pedagogia e de Sociologia da Educação. De seguida, após a compreensão da dinâmica planificada, apostámos numa sistematização dos principais objectivos enunciados em torno do que consideramos os principais vectores do projecto.
$\mathrm{Na}$ segunda etapa do procedimento de avaliação, procurámos aceder ao projecto na sua concretização prática, através de realização e análise de entrevistas estruturadas (junto aos alunos do primeiro e do segundo ciclo do ensino básico, dos seus encarregados de educação, dos monitores e formadores do projecto, dos representantes das entidades em colaboração e dos representantes das principais entidades locais). Neste sentido, escutámos e articulámos os discursos críticos sobre o projecto, tendo em conta a percepção de resultados e os objectivos perspectivados no plano inicial do projecto. A este nível foram planificadas medidas mais concretas para averiguar os efeitos do projecto: a observação comparativa entre aulas do projecto e aulas regulares; a aplicação de um inquérito de ocupação de tempos livres, a alunos do secundário, que participaram e que não participaram no projecto; e a análise estatística das notas finais das crianças do primeiro ciclo, do concelho de Vila Velha de Ródão, entre os anos lectivos 2000/01 e 2006/07.

A proposta inicial foi aceite por parte do CENTA. Contudo, a interpretação institucional divergente do Agrupamento de Escolas, combinado com os constrangimentos formais e a rigidez das rotinas que caracterizam os órgãos de gestão educativa, culminou na transposição das actividades de investigação para fora do espaço escolar e a consequente reestruturação do plano de avaliação com a eliminação da observação comparativa das aulas. A análise estatística perspectivada também não foi realizada. A informatização dos dados requeridos foi tardia. Consequentemente, o Agrupamento de Escolas apenas conseguiu disponibilizar as notas referentes aos anos lectivos 2005/06 e 2006/07. A ideia desta análise seria de comparar a evolução de classificações num momento anterior e posterior à aplicação do PFAC. Os dados disponibilizados não permitem essa comparação, dado serem coincidentes com o início do próprio projecto.

\section{A educação artística num território fragilizado}

Um projecto educativo surge de um conjunto de acções organizadas para determinado fim pedagógico. A concepção, planificação e concretização da constelação de actividades, necessárias para a sua aplicação, implica uma mobilização importante dos diversos recursos e agentes disponíveis em determinado contexto.

Sabe-se que toda a acção humana tem origem numa energia "geradora de forças" que dinamiza os protagonistas das actividades. Essa energia, em Psicologia, é designada por motivação, sendo imprescindível para um conhecimento profundo do comportamento humano a abordagem à sua 
origem - os sociólogos referem-se à sua génese social...(Abreu, 2002). Paralelamente, para a compreensão de um projecto educativo é necessário o conhecimento do seu ponto de partida. Neste caso, as potencialidades da Educação Artística e os recursos e fragilidades do concelho são elementos contextuais fundamentais na génese do Projecto de Formação Artística Contínua.

Educação Artística e a Educação Artística no ensino português

A Educação artística consiste num movimento pedagógico que visa contribuir para o desenvolvimento completo e harmonioso do agente social. Através do ensino específico de disciplinas artísticas ou da utilização de conhecimentos das áreas artísticas para abordar outras temáticas, os profissionais de Educação Artística investem no desenvolvimento de competências individuais e inter-subjectivas, do foro cognitivo e emocional, como a criatividade, imaginação, crítica, autonomia ou inteligência emocional, que são consideradas fundamentais para corresponder às necessidades da sociedade contemporânea. Com estas acções, ao mesmo tempo, valoriza-se o capital cultural local e promove-se a diversidade de expressões artísticas (CNEA, 2004).

$\mathrm{Na}$ evolução dos estudos sobre o desenvolvimento hum ano tem-se vindo a constatar que, apesar de serem detectadas regularidades na formação da vida mental das crianças, o sistema educativo marca as suas trajectórias, o que enfatiza a necessidade de um sistema de ensino de qualidade para a formação total dos cidadãos (Gardner, 1994). Neste âmbito, não podemos deixar de ter em conta que nas escolas ocidentais persiste um privilégio sobre as competências lógicas e formais, em detrimento das aprendizagens através da manipulação ou experimentação, o que condiciona uma aprendizagem que se quer global, constituindo um factor de inibição da componente afectiva da aprendizagem (Weber, 2004). É de salientar que as actividades artísticas proporcionam um terreno fértil para o estímulo de competências cognitivas, uma vez que envolvem a manipulação de diversos símbolos e de competências expressivas e emocionais, pela oportunidade que oferecem para exteriorizar a vida interior das crianças, constituindo, assim, uma ferramenta pedagógica muito interessante (Gardner, 1994).

A Educação Artística refere-se, portanto, a uma educação com objectivos orientados para o desenvolvim ento harmonioso da personalidade, implicando uma acção equilibrada nas diferentes esferas do sujeito, mediante uma perspectiva holística do ser humano. Na legislação nacional sobre a Educação (Constituição Portuguesa) e sobre o Ensino (Lei de bases do sistema educativo) existe uma clara definição educacional voltada para o desenvolvimento da personalidade e para os valores espirituais, estéticos e morais, objectivos esses claramente equivalentes aos atribuídos à Educação pela Arte. Para as entidades legislativas e regularizadoras do ensino em Portugal, as valências preconizadas por esta abordagem pedagógica são essenciais e constituem-se mesmo como direitos fundamentais dos cidadãos portugueses (Sousa, 2003).

As fragilidades de um concelho

No âmbito da Sociologia da Educação tem-se verificado, através de vasto património científico acumulado, uma forte ligação estatística entre a origem de classe dos estudantes e os seus níveis de sucesso escolar (Pinto, 2002). Como tal, a constatação de fragilidades sociais, que aqui pretendemos apresentar, devem consistir um factor mobilizador (e não a mera reiteração de uma fatalidade social) para um empenho acrescido nas políticas e projectos educativos.

O concelho de Vila Velha de Ródão, do distrito de Castelo Branco, situa-se na fronteira entre a Beira e o Alto Tejo e é constituído por quatro freguesias (Fratel, Perais, Sarnadas de Ródão, e Vila Velha de Ródão) que ocupam $328 \mathrm{~km} 2$. Consiste numa zona xistosa com um apreciado património natural onde se destacam os grandes vales em contraste com extensas zonas de planície. É banhado pelos rios Tejo, Ocreza e Pônsul.

Demograficamente caracteriza-se como uma localidade desertificada e claramente envelhecida. Segundo os Censos de 2001, residem no concelho de Vila Velha de Ródão 4098 pessoas, 1956 homens e 2133 mulheres situados maioritariamente nas faixas etárias entre os 65 a 79 anos. De acordo com os dados estatísticos fornecidos pelo INE (Instituto Nacional de Estatística), o índice de densidade populacional, que calcula o número de habitantes por $\mathrm{km}^{2}$, tem vindo a diminuir ao longo dos anos, sendo que em 2005 tinha um valor 10 vezes inferior ao valor referente a Portugal $(11,4$ e 114,78 habitantes por $\mathrm{Km}^{2}$, respectivamente). Por outro lado, o índice de envelhecimento apresenta um crescimento muito acelerado e, como podemos verificar no Gráfico 1 , esta tendência parece acentuar-se nos últimos 6 anos. Os dados mais recentes apontam para um índice de envelhecimento na ordem de 552\%. Para o mesmo ano, em Portugal, na relação entre a população idosa e a população jovem, foi registado o valor de $110 \%$.

Associados a este panorama encontramos outros indicadores de uma situação social desvantajosa em relação ao país. Em 2001, Vila Velha de Ródão possuía uma taxa de analfabetismo de $20 \%$, mais que o dobro da nacional ( $9 \%$ ), e apresentava uma taxa de actividade de $36,4 \%$, sendo que 6,4 $\%$ da população activa encontrava-se em situação 
de desemprego, contra a percentagem de 3,9 da média nacional (INE, Anuário Estatístico, 2002). De notar ainda que, a nível deste concelho, encontramos uma clara predominância de trabalhadores não qualificados (Gráfico 2).
No que diz respeito aos níveis de qualificação da população de Ródão verificamos, com a ajuda do Gráfico 3, que quase metade da população residente possui nenhuma qualificação literária ou apenas a qualificação equivalente ao primeiro ciclo do ensino

Gráfico $1 \triangleright$ Evolução do índice de envelhecimento (\%)

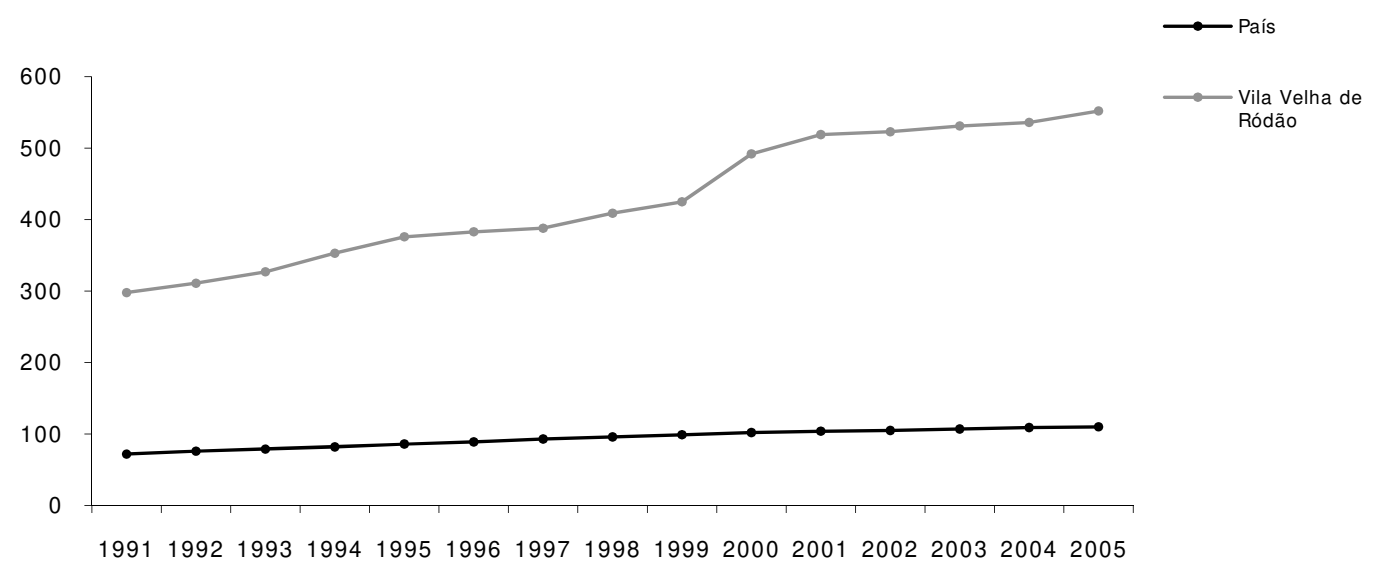

Fonte: INE, O país em números

Gráfico $2 \triangleright$ População empregada segundo os grupos profissionais (\%)

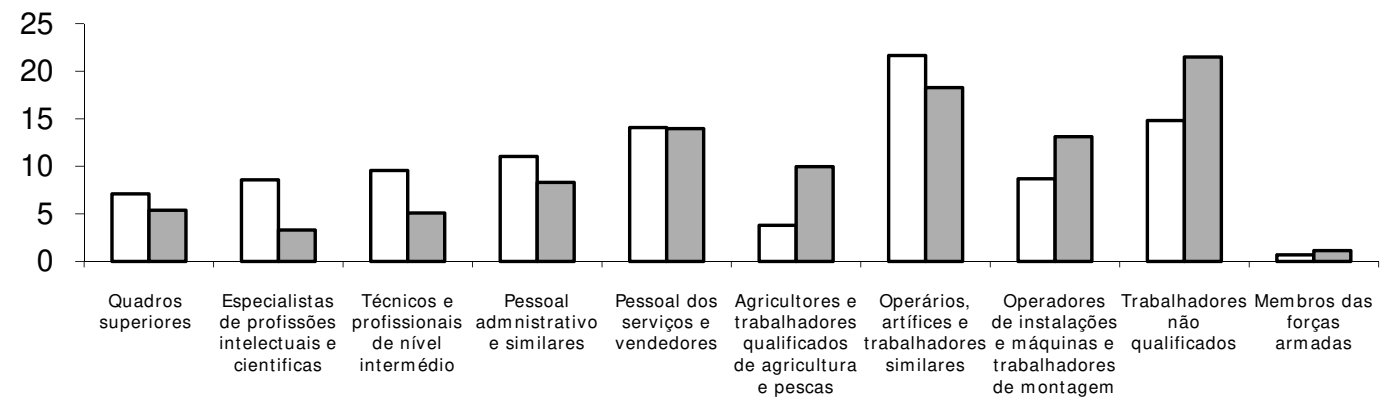

Fonte: INE, Censos 2001

Gráfico $3 \triangleright$ População residente segundo o nível de qualificação (\%)

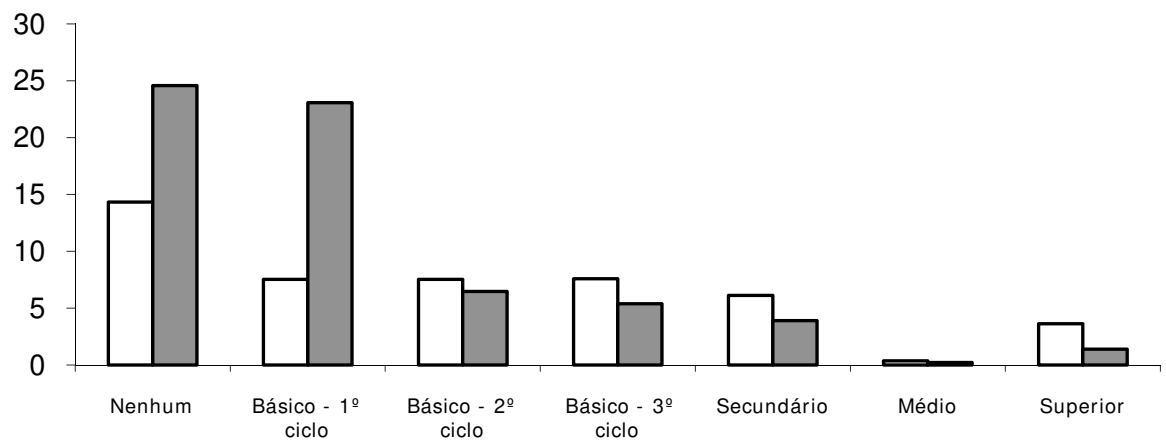

Fonte: INE, Portugal em números, 2001 
básico $(47,6 \%)$. De notar que "apenas" 21,8\% da população portuguesa é caracterizada pelos mesmos níveis de qualificação.

Vila Velha de Ródão revela-se, através destes indicadores estatísticos, como um concelho pautado por sérias limitações sócio - demográficas, principalmente no que concerne à qualificação da população.

Poderíamos inferir que este panorama resultaria em grandes restrições no que diz respeito ao sucesso escolar das crianças da localidade. Contudo, segundo Pinto (2002), os factores sociais que explicam os níveis de sucesso escolar devem ser analisados na sua complexidade, tendo em conta os diferentes patamares de análise. O autor defende que o sucesso escolar poderá ser analisado tendo em conta as dinâmicas que se estabelecem entre os factores atribuídos à "origem e trajectória de classe dos alunos", aos "percursos escolares" (Pinto, 2002:8) específicos de cada agente, que se regem segundo os seus recursos individuais e familiares, sendo muitas vezes configurados pelas características do sistema de ensino, e pela "vocação pessoal" (idem:9), criada mediante diferentes factores ligados à origem de classe e modalidades de socialização.

Atendendo a que estas relações não são simples ou lineares, importa aqui salientar, para além da importância dos factores de origem social, o papel do sistema de ensino (do funcionamento das instituições ou das relações entre o aluno e a escola) enquanto elem ento importante onde o investimento é necessário e pertinente para o sucesso escolar. Por outras palavras, para além das fragilidades do território, as culturas organizacionais das escolas e os recursos educativos do concelho também possuem um papel significativo ao nível da trajectória escolar das crianças.

\section{Horizontes e expectativas do projecto}

Com base no contexto social e educacional descritos, a colaboração entre o CENTA e o Agrupamento de Escolas estabeleceu-se com a organização de ateliês artísticos para crianças do primeiro ciclo, evoluindo, posteriormente, para uma proposta de formação artística contínua no ano lectivo de 2003/04. Inicialmente, o projecto possuía um enquadramento formal muito débil sendo que, apenas no ano lectivo de 2005/06, após um ano de interregno, é formalmente aprovado pelo Conselho Pedagógico do Agrupamento de Escolas. Este cenário repete-se no ano lectivo seguinte, 2006/07, que consiste no foco da nossa análise.

O PFAC visa contribuir para o sucesso dos processos de ensino e aprendizagem através da inclusão da Educação Artística no ensino primário, considerando a importância de experiências criativas e multidisciplinares no desenvolvimento das crianças. Propõe a articulação entre práticas artísticas e pedagógicas como estímulo à criatividade e como facilitador do processo de aquisição de conteúdos programáticos de Língua Portuguesa e Estudo do Meio. Pretende reforçar a identidade cultural das crianças, ao mesmo tempo que se envolvem os alunos, pais, familiares e outros elementos da comunidade em torno do processo educativo dos alunos.

Os objectivos do projecto são viabilizados com a organização de actividades, inseridas no horário curricular, que permitem a todas as crianças do primeiro ciclo do ensino básico do concelho de Vila Velha de Ródão o acesso a 2 horas semanais de formação artística nas áreas de Dança e de Artes Plásticas (alternadamente), facultadas por monitores especializados. Esta equipa de formadores do projecto é constituída por artistas que, no desenvolvimento do seu trabalho de criação, valorizam uma articulação com a comunidade.

O programa é construído sob a lógica do processo e da continuidade, assegurando, consequentemente, uma articulação conceptual e temporal entre os conteúdos curriculares abordados nas aulas das duas áreas artísticas.

Num momento inicial, os professores participam numa acção de formação sobre o projecto e escolhem os conteúdos curriculares que consideram mais pertinentes. Pretende-se, com estas acções, que os docentes usem o projecto como uma ferramenta pedagógica ao seu dispor.

Para a monitorização do projecto, a proposta de trabalho aponta para a necessidade de agendar reuniões regulares com os professores e os monitores, a entrega de relatórios das actividades desenvolvidas e a colaboração com uma entidade externa. Também para esse fim, são planificados momentos de interacção com os encarregados de educação das crianças (Aulas Abertas) e com a comunidade em geral (Exposições Finais). Para além destas indicações formais, em anos anteriores, o corpo de docentes reunia-se no final de cada período e produzia um parecer colectivo sobre o projecto, a entregar posteriormente à equipa do CENTA.

As actividades do PFAC pretendem desenvolver uma série de capacidades nas dimensões constitutivas do desenvolvimento da criança. Do ponto de vista cognitivo, a Educação Artística, que subjaz à organização deste projecto, investe ao nível da imaginação, invenção e criação dos sujeitos, procurando ir além da inteligência associativa. Nesse sentido, as actividades propostas procuram proporcionar um cenário em que as crianças possam aplicar, treinar e desenvolver a sua criatividade, capacidade de observação, de concentração, de decisão, de realizar analogias, ou de decidir face a desafios.

Ao mesmo tempo, identifica-se uma tónica no movimento, na acção e na experimentação. Visa-se 
trabalhar a coordenação motora e a lateralidade e contribuir para um maior protagonismo das crianças no processo da sua aprendizagem.

Noutra perspectiva, as aulas do projecto encerram em si uma importante dimensão emocional. Os monitores pretendem fazer do PFAC um espaço para a expressão pessoal das crianças e para o estabelecimento de relações afectivas positivas entre os alunos, entre os alunos e os seu monitores, e entre os alunos e as próprias actividades desenvolvidas. Procura-se entusiasmar as crianças em torno do projecto e contribuir para o desenvolvimento da auto-confiança e auto-conhecimento.

As interacções entre os alunos e os professores na sala de aula são configuradas por uma série de códigos de conduta já há muito institucionalizados. Em oposição, as propostas do PFAC distanciam -se do ensino normalizado ao fomentarem as interacções socais num contexto muito menos constrito às regras habituais. Ao longo de todas as sessões do projecto o trabalho de grupo é privilegiado. Pretende-se estimular a percepção do outro e a integração de regras e recursos sociais subjacentes à formação cívica dos alunos.

A concepção das actividades do projecto decorre em torno das temáticas seleccionadas pelos professores. No ano lectivo em análise, a dimensão curricular do projecto prendia-se com a expressão e compreensão verbal e não verbal de conteúdos pertencentes à disciplina de Língua Portuguesa (ex.: nomes, verbos, adjectivos, antónimos e sinónimos) e às temáticas do Estudo do Meio (ex.: reciclagem, sustentabilidade, geometria, profissões, cidadania).

O PFAC propõe a utilização de conceitos e práticas oriundas das áreas artísticas. Por conseguinte, as sessões do projecto proporcionam simultaneamente oportunidades de realizações criadoras, como a construção de objectos, expressão dramática ou a exploração do movimento no espaço, e de aplicação de técnicas, como o recorte, desenho e colagem nas Artes Plásticas ou o treino e persistência na Dança. Paralelamente, planeia-se abordar alguns conceitos artísticos, como o de instalação, de efémero, de reflexão sobre elementos naturais na arte, a composição ou a escultura. As aulas do projecto visam, da mesma forma, potenciar o desenvolvimento de competências específicas a cada domínio. Por exemplo, nas Artes Plásticas abordam-se noções de bi e tridimensionalidade, enquanto que nas aulas de Dança estimula-se a sincronia e o ritmo.

Tendo em conta as dificuldades da missão docente, o projecto disponibiliza profissionais especializados nas áreas artísticas para auxiliar os professores na abordagem de alguns conteúdos. Espera-se que os professores tomem o PFAC como uma ferramenta pedagógica, de modo a rentabilizarem a sua intervenção educativa através das sessões desenvolvidas neste âmbito.
Em suma, com base nos objectivos delineados, espera-se que a contribuição do PFAC ao nível do binómio ensino/aprendizagem se traduza em mudanças nas dimensões individual, social, curricular e artística das crianças alvo. Da mesma forma, o projecto perspectiva transformações disposicionais no corpo de docentes do primeiro ciclo e na comunidade em geral.

É importante considerar que estas mudanças estão pensadas a longo prazo, segundo a continuidade do projecto e os mecanismos da Educação Artística. Não perdendo de vista esta consideração, espera-se que as crianças se empenhem nas actividades propostas, e que os adultos mais próximos percepcionem alterações no seu comportamento, potencialmente derivadas do projecto.

\section{Distâncias entre o projecto planificado e o projecto concretizado}

Tal como fora planeado, o PFAC iniciou-se, em Setembro, com uma acção de formação para os professores, onde o projecto foi apresentado, conjuntamente com os conceitos curriculares mais pertinentes seleccionados pelos docentes. Os relatórios das actividades foram igualmente entregues aos professores, no final de cada período, tendo em conta as datas das reuniões de avaliação do projecto.

O segundo momento de reunião, já no segundo período, ocorreu no mês de Fevereiro, sendo que não aconteceu como planificado no mês de Dezembro, devido ao reduzido número de aulas verificadas até então. Nessa data, foram definidos novos conteúdos curriculares e realizou-se uma reflexão crítica sobre as aulas do PFAC, em que se valorizou o projecto, na sua generalidade, e apontou-se para o excesso de "barulho" vivido nessas actividades.

No terceiro período, a monitorização em curso foi interrompida. O Corpo de Docentes do primeiro ciclo não convocou a reunião planificada para esse fim. A impossibilidade de um terceiro momento de reunião impediu a continuação da troca de perspectivas entre os profissionais envolvidos e a aprovação da proposta de avaliação do Instituto de Sociologia, em tempo útil para ser apresentada em Conselho Pedagógico. Por outro lado, esta situação levou a que a equipa do projecto só tivesse acesso à avaliação final do PFAC, efectuada pelos professores, num momento posterior ao das decisões sobre ele realizadas. Como efeitos desta avaliação interna, o Conselho Pedagógico decidiu transpor o PFAC para o horário extracurricular, sem que nessa decisão tivessem participado os elementos do CENTA. 
Aquisições do projecto

\section{Dimensão Individual}

$\mathrm{Na}$ escala individual, o projecto procura ter efeitos no domínio afectivo, cognitivo e motor.

Todos os encarregados de educação inquiridos falaram da adesão entusiasta dos seus educandos às actividades propostas:

"As primeiras coisas que ela [educanda] contava da escola com um verdadeiro interesse eu senti que era o CENTA (...) Se eles recontam é porque eles se interessaram e eu senti que era importante para eles"; "Eles adoram"; "Quando eles estão ali, eles estão contentes!".

Ainda no domínio emocional, menciona-se a relação de proximidade entre os monitores e as crianças enquanto um dos pontos mais positivos do projecto:

"Gostei de ver, sei que trabalham [equipa CENTA] com bastante amor, gostam daquilo que fazem e gostam que as pessoas valorizam aquilo que fazem"; "É uma disciplina que faz com que os miúdos desenvolvam um bocado e dá-Ihe uns laços que possivelmente noutra altura não os ganham".

Para além do investimento emocional das crianças, os encarregados de educação encaram o projecto como sendo especificamente relevante para os seus educandos, uma vez que valoriza a criatividade e expressão (a maioria dos educandos foram descritos como reservados ou tímidos), permite a gestão do insucesso através da valorização do processo e proporciona experiências descontraídas e lúdicas:

\footnotetext{
"É bom para ela [educanda] ser mais comunicativa"; " [Ao longo do tempo] continuei a sentir interesse que os projecto que se desenvolviam que eram importantes para eles, que apelavam à criatividade"; "Intelectualmente leva-os a outros níveis"; "Eu vejo que a minha filha não sabe lidar bem com o insucesso (...) o projecto é importante porque eles começam a aprender a fazer alguma coisa pode não estar muito bem mas que vão trabalhando".
}

Por outro lado, os encarregados de educação assistiram a evoluções nas suas crianças ao nível da expressão corporal e da gestão de movimentos no espaço:

"A expressão corporal existe muito mais"; "Vejo [evoluções] na parte dos gestos da parte do comportamento eu acho que eles se sabem bem gerir o espaço, o que é para fazer e o que não para fazer"; "Ele está sempre a mexer-se! Dantes, quando estava no infantário, mal se mexia!".

Da mesma forma, os professores destacaram a dimensão emocional do projecto, salientando a relação pedagógica e empática estabelecida e a importância deste tipo de projectos para a comunicabilidade e expressão pessoais.

Os monitores, por sua vez, constataram evoluções na esfera cognitiva, nomeadamente crescentes manifestações de criatividade, curiosidade, abstracção e até de memória e associação de conceitos, quando as crianças se recordam das actividades anteriores e as relacionam entre si; na esfera afectiva, sentida através do entusiasmo das crianças; na relação pedagógica e empática estabelecida e na evolução da postura das crianças para uma crescente vontade de explorar e também na esfera motora, com a percepção da diminuição de défices na expressão verbal e psicomotora:

[Foram identificadas mudanças] "na maneira como eles absorvem a aula, a curiosidade, a resposta que dão ao exercício, ao lado criativo, pôr as coisas em perspectiva, fazer um esboço", na "criação de movimentos (...) não tinham essa facilidade (...) agora que têm uma grande capacidade de criação, de propor novos movimentos".

E na persistência face aos desafios ("já sabem que não vou ajudar, ajudo no que for preciso, mas eles têm de tentar primeiro"). Ainda se refere:

"o facto de eles ligarem e lembrarem os conteúdos (...) mais tarde eles próprios relacionarem umas coisas com as outras"; "Notei uma desenvoltura enorme, notei que eles gostavam de facto das aulas, que se desempenhavam, que o facto deles saberem que dali ia sair alguma coisa, um objecto do qual eles se orgulhavam, de um trabalho, eles se empenhavam de facto"; "Nas minhas aulas as crianças começaram a ser muito mais expressivas a nível verbal e não verbal, conseguiam se expressar muito melhor".

Em discurso directo, verificamos que, tal como se tinha previsto, os alunos parecem altamente entusiasmados com o projecto: $78 \%$ dos entrevistados referem o PFAC como a sua actividade preferida na escola e $91 \%$ das crianças incluídas no estudo realizam actividades artísticas que aprendem no projecto em espaço extra-escolar. Entrevistámos, também, alunos ex-participantes do projecto que, 


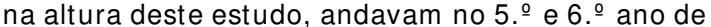
escolaridade. Este grupo guardava uma recordação positiva das actividades e conseguia ainda referir e descrever as suas actividades preferidas, o que advoga a favor da proposição inicial.

\section{Dimensão Social}

Segundo os depoimentos dos encarregados de educação, o PFAC intervém nas competências sociais das crianças a dois níveis: individual e colectivo. No primeiro nível, alguns alunos beneficiaram do projecto para se tornarem pessoas mais abertas e disponíveis no contacto com o outro. No segundo nível, foi mencionado que, com base no trabalho desenvolvido na aplicação do projecto em anos anteriores, a turma de Porto do Tejo 1 obteve uma grande melhoria no seu comportamento na sala de aula:

\footnotetext{
"Noto que ele [o educando] está uma pessoa muito mais aberta"; "Eu conheço-os desde o jardim-de-infância, e eram muito barulhentos, as regras para eles não existiam, não eram aqueles miúdos mal-educados propriamente ditos, mas eram aqueles miúdos que não conseguiam estar calados e que não conseguiam organizar-se, era muito difícil conseguir que eles se organizassem e nota-se uma grande evolução no grupo".
}

No discurso dos professores entrevistados verifica-se uma tónica no desenvolvimento da esfera social das crianças. Ao que parece, as actividades têm um papel na comunicabilidade e ajustamento social do comportamento dos alunos. Foi mencionado, inclusivam ente, um caso de particular destaque, na escola de Fratel, em que, apesar dos seus grandes défices a nível do desempenho escolar e de interacção social, o aluno envolvia-se notoriamente nas actividades de artes plásticas:

"O T. tinha muitas dificuldades familiares sociais e que o levavam a ter muitas dificuldades cognitivas e também de relacionamento na sala de aula...era um miúdo que simplesmente brincava debaixo de uma mesa (...). Em diversas aulas o T. saía daquela toca dele e daquele ser animal que ele era, para se dedicar $1 \mathrm{~h}$ ou $2 \mathrm{~h}$ às vezes numa actividade... um primeiro passo... consolidando esta experiências ele poderia aliar este esta atitude este estar a brincar com as cores e o desenho que ele se entregava imenso com as aprendizagens curriculares."

\section{Dimensão Curricular}

As actividades do PFAC articulam conteúdos curriculares com conteúdos artísticos. Apesar deste aspecto ser referido como um dos pontos fortes do projecto, no que diz respeito à percepção de resultados a este nível encontramos apenas uma única referência: no âmbito da entrevista com a Associação de Pais, salientou-se o papel do PFAC na aquisição do conceito de pontuação: "[Através do PFAC] Foi a maneira mais fácil de aprenderem a pontuação, e mesmo os que tinham dificuldades ficaram a perceber aquilo. Foi uma maneira de fazer chegar aquela mensagem".

\section{Dimensão Artística}

Em relação à dimensão artística do projecto, na óptica dos encarregados de educação, o PFAC contribuiu para a maior disponibilidade das crianças no que se refere a experiências artísticas. Alguns dos pais entrevistados enunciaram mesmo evoluções dos seus educandos ao nível da dança e no desenho. Os professores, por sua vez, mencionam efeitos ao nível da manipulação de materiais e na postura criativa nas actividades. No caso dos monitores, foram mencionados níveis crescentes de familiaridade e manipulação da linguagem artística: "Sinto que eles começam... é como eles tivessem aprendido uma língua, como tivessem aprendido uma língua e tivesse a ganhar cada vez mais vocabulário e sentir-se cada vez mais à vontade de a usar...".

\section{Inquérito sobre a ocupação de tempos livres}

Com base na aplicação de um inquérito sobre a ocupação de tempos livres, tentámos verificar se existiriam diferenças entre os alunos que participaram e que não participaram no PFAC, no modo como ocupam os seus tempos livres. Mais especificamente, procurámos comparar os alunos do 7.9 e 8. ano (alunos Participantes e Não Participantes, respectivamente), ao nível do envolvimento em actividades culturais de produção criativa, três anos depois do início do projecto.

Para garantir a validade desta análise tivemos de atender aos sujeitos simultaneamente reincidentes e pertencentes ao 7. ano (uma vez que respeitam ao grupo dos não participantes do projecto), à variável idade (eliminando os alunos com mais de 17 anos) e ao contexto familiar dos inquiridos, de modo a assegurar a homogeneidade dos dois grupos. Feitas estas considerações, dos 30 alunos inquiridos 27 são incluídos na amostra analisada, que é constituída por 10 participantes e 17 não participantes do PFAC, com idades compreendidas entre 13 e 16 anos.

Em consonância com os dados estatísticos apresentados pelo INE, os encarregados de educação 
dos nossos inquiridos possuem níveis de habilitação literária relativamente baixos. Ao nível da amostra total, a maioria possui o $2 .{ }^{\circ}$ ciclo do ensino básico ( $52 \%$, no caso dos pais do sexo masculino e $46 \%$, no caso dos pais do sexo feminino). Em segundo lugar, $32 \%$ no caso dos homens e $38 \%$ no caso das mulheres detêm o 1.0 ciclo, sendo que, apenas $16 \%$ dos responsáveis possuem o nível de ensino secundário ( $16 \%$ no caso dos homens e $15 \%$ no caso das mulheres). Estas tendências foram encontradas nos dois grupos que foram comparados. Contudo, os não participantes do PFAC têm responsáveis com níveis de habilitações mais elevados. É neste âmbito que encontramos a grande maioria de encarregados de educação com o ensino secundário e onde as diferenças entre os géneros são mais esbatidas. Considerando que os factores intra-familiares contribuem para acessibilidade a determinados bens culturais (capital cultural objectivado), podemos deduzir uma eventual vantagem deste grupo face aos participantes do projecto.

O inquérito foi construído a partir de uma lista de actividades normalmente empreendidas pelos jovens portugueses, sintetizada num trabalho de Pais (1982). Ao nível das instruções de aplicação, pedia-se aos sujeitos que indicassem a frequência com que realizavam cada uma das actividades indicadas. Para fins estatísticos, a totalidade das questões do inquérito foi organizada em quatro conjuntos: Actividades Culturais de Recepção; Actividades Culturais de Produção; Actividades de Lazer ou de Sociabilidade e Jogos e Internet. Para o mesmo fim, as respostas dos alunos foram posteriormente codificadas numa escala ordinal de 7 níveis, que permitiu a criação de índices de frequência médios de cada actividade.

$\mathrm{Na}$ análise dos resultados constatámos que o conjunto Jogos e Internet é o tipo de actividade mais empreendida pelos jovens nos seus tempos livres. A este nível, o item com o maior índice médio de frequência é "Jogar Consolas", sendo o "Conversar em Chats" o que possui um valor mais baixo.

Em segundo lugar encontrámos as Actividades de sociabilidade e lazer. O seu destaque não nos surpreendeu, uma vez que este conjunto engloba vários itens que se referem a actividades muito acessíveis ao quotidiano dos jovens. A actividade mais popular neste grupo era "Fazer passeios ao ar livre", e a menos frequente consistia em "Ir a bares ou discotecas" (todos os sujeitos da amostra são menores).

As Actividades Culturais de Recepção encontravam-se em terceiro lugar, com um claro destaque da música e da T.V. no tem po livre dos inquiridos e uma representação residual na "Participação de reuniões culturais, conferências, ou actividades do género".

Para finalizar, as Actividades Culturais de Produção eram as menos representadas nos tempos livres destes jovens. Dentro deste conjunto, o item com os maiores valores de frequência era "Fazer dança clássica, rítmica, danças de salão ou contemporânea" e a actividade menos incidente consistia em "Fazer fotografia".

O objectivo do Projecto de Formação Artística Contínua não seria a reconfiguração do modo de ocupação de tempos livres dos jovens, até porque as tendências encontradas estão possivelmente ligadas às culturas juvenis locais. Uma vez que o PFAC se propõe apresentar actividades criativas às crianças, estimulando o empenho voluntário em tarefas de criação, procurámos centrar a nossa análise ao nível das Actividades Culturais de Produção.

Utilizando uma vez mais o índice médio de frequência de cada uma das actividades seleccionadas, verificámos que as diferenças entre os grupos eram muito ténues. No grupo dos Participantes existia uma tendência superior, em relação ao Não Participantes, para realizar "Trabalhos manuais", "Escrever contos ou poemas" e "Ir ou fazer teatro". Ao mesmo tempo, os Não Participantes pareciam empreender com mais frequência as actividades "Pintar e desenhar", "Fazer fotografia" ou "Tocar um instrumento musical" (Quadro 1). Por outras palavras, no âmbito das Actividades Culturais de Produção, entre os Participantes e os Não Participantes, não encontrámos um destaque particular de um grupo em relação ao outro, na medida em que se detectou a dominância relativa em cada grupo de um mesmo número de actividades.

Contudo, se focarmos um pouco mais a lente da nossa perspectiva, e tivermos em conta unicam ente as actividades que dizem directamente respeito ao PFAC, os Participantes revelam um maior índice de frequência em relação aos Não Participantes em 2 das 4 actividades directamente associadas ao projecto (Quadro 1).

Em síntese, os resultados decorrentes da aplicação do inquérito sobre a ocupação de tempos livres indiciam algumas diferenças entre os grupos de sujeitos ao nível das actividades directamente associadas ao PFAC. Os valores parecem confirmar a ideia que o projecto tem um certo impacto sobre a recorrência com que os jovens realizam determinados tipos de actividades. Contudo, a expressão dos resultados revelou-se ténue e apenas presente num nível de análise muito específico, ou seja, os Participantes e Não Participantes do projecto distinguem-se somente nas Actividades Culturais de Produção directamente relacionadas com o projecto. É de salientar que os alunos Participantes apenas tiveram acesso parcial ao projecto. O PFAC assenta numa ideia de continuidade, apostando no acompanhamento das crianças ao longo dos quatro anos do primeiro ciclo do ensino básico. Os alunos do 7. ano incluídos nesta análise apenas participaram no projecto durante o seu quarto ano de escolaridade. 
Quadro $1 \triangleright$ Índice médio de frequência das Actividade Culturais de Produção por grupo de sujeitos

\begin{tabular}{|l|l|c|}
\hline \multicolumn{1}{|c|}{ Grupo de sujeitos } & \multicolumn{1}{|c|}{ Actividade } & \multicolumn{1}{c|}{$\begin{array}{c}\text { Índice médio } \\
\text { de frequência }\end{array}$} \\
\hline \multirow{5}{*}{ Participantes do PFAC } & Pintar ou Desenhar* & 2,4 \\
\cline { 2 - 3 } & Trabalhos Manuais* & 0,5 \\
\cline { 2 - 3 } & Dança* & 1,5 \\
\cline { 2 - 3 } & Teatro* & 1,6 \\
\cline { 2 - 3 } & Escrever & 1,2 \\
\cline { 2 - 3 } & Fotografia & 1,8 \\
\cline { 2 - 3 } & Tocar um Instrumento musical & 3,1 \\
\hline \multirow{5}{*}{ Não Participantes do PFAC } & Pintar ou Desenhar* & 2,2 \\
\cline { 2 - 3 } & Trabalhos Manuais* & 0,5 \\
\cline { 2 - 3 } & Dança* & 1,4 \\
\cline { 2 - 3 } & Teatro* & 1,5 \\
\cline { 2 - 3 } & Escrever & 1,9 \\
\cline { 2 - 3 } & Fotografia & 2,2 \\
\cline { 2 - 3 } & Tocar um Instrumento musical & \\
\hline
\end{tabular}

* Actividades directamente associadas com o PFAC

A suposta fragilidade das tendências encontradas pode ser explicada à luz das considerações realizadas sobre o contexto familiar dos inquiridos. O grupo dos Não Participantes parece estar associado a contextos familiares mais vantajosos, em relação ao grupo dos Participantes. Esta assimetria poderá ter camuflado o benefício eventualmente proporcionado pelo PFAC ao nível da ocupação de tempos livres.

Por outro lado, a proximidade entre os dois grupos analisados poderá ser compreendida como resultado das mais-valias do projecto que funcionaram como atenuantes das diferenças familiares encontradas entre os Participantes e os Não Participantes do PFAC.

\section{Percepções diferenciais sobre o projecto}

Pólo da oferta

Representações do corpo de docentes do primeiro ciclo e do presidente do Agrupamento de Escolas

Segundo os depoimentos recolhidos, os professores detectaram uma série de aspectos positivos nas actividades que eram propostas aos alunos. As aulas do projecto eram interessantes e entusiasmavam as crianças ao mesmo tempo que consolidavam aprendizagens do currículo e desenvolviam "diferentes competências do aluno", destacando-se neste ponto o papel do PFAC ao nível do pensamento criativo e da desenvoltura social. Nesse sentido, o projecto foi caracterizado de "inovador e pedagógico".

Ao mesmo tempo, a intervenção dos monitores também foi valorizada pelo corpo docente. O empe- nho nas actividades que a equipa do CENTA revelou $\mathrm{e}$ a relação em pática que estabeleceu com as crianças contribuíram como pontos fortes do projecto.

Em oposição, os docentes alertaram, simultaneamente, para a impossibilidade de assegurar continuidade entre as aulas do projecto e as aulas regulares, devido ao desconhecimento do momento em que os monitores iriam abordar os temas; para a escassa articulação com os conteúdos curriculares; para a não articulação das aulas do projecto com as festividades ao longo do ano e para a incapacidade de envolver algumas das crianças. Estas fragilidades contribuíram para que os professores considerassem que o PFAC não deveria estar inserido em horário curricular.

O PFAC era, por vezes, um elemento perturbador na gestão da missão docente, principalmente devido aos episódios de falta de pontualidade e mudanças de horários, de comportamentos que colocavam em causa a figura de autoridade do professor titular e da já mencionada desarticulação entre aula e o projecto.

O presidente do Agrupamento de Escolas, para além de referir alguns destes pontos, chama a atenção para a ausência de mecanismos de monitorização eficazes. As percepções de aspectos negativos foram dificilmente canalizadas para a equipa de terreno do CENTA, ao longo do ano e, especialmente, de um ano para o outro, porque não existiam reuniões definidas para tal. As acções avaliativas que decorriam no final de cada período resumiam-se à apresentação de relatórios finais por cada uma das partes, sendo pontuados pela ausência de debate e comparação de discursos. 
Na perspectiva do Agrupamento, todos estes problemas estariam relacionados com os processos de articulação entre as estruturas envolvidas. Se, por um lado, uma parceria entre o Agrupamento de Escolas e o CENTA se revestia de interesse e pertinência, mesmo segundo uma perspectiva mais alargada do que a actual, essa colaboração não teria sido muito eficaz.

O impedimento inicial da prossecução do actual estudo em espaço escolar poderá ser considerado como uma consequência dessas dificuldades. $\mathrm{Na}$ proposta de trabalho do PFAC, aprovada em Conselho Pedagógico, estaria prevista uma avaliação do projecto por uma entidade externa. Contudo, considerando que a avaliação do projecto deveria ser contínua, e não apenas pontual, e que, como tudo neste projecto, seria necessária uma total parceria entre as entidades envolvidas, as acções do CENTA realizadas autonomamente não foram aceites, o que culminou com o impedimento do projecto de avaliação do Instituto de Sociologia nas escolas do agrupamento.

O agrupamento garantiu que não se opunha ao PFAC, mas entendia o projecto de um modo diferente. O PFAC não seria considerado enquanto um projecto de educação artística, mas sim como um programa que visava o reforço ao nível das aprendizagens no âmbito da Língua Portuguesa e do Estudo do Meio. Ao longo do tempo foi-se constatando que o projecto se desviava da sua planificação inicial e, como tal, teriam sido tomadas acções para o seu ajustamento.

Segundo o representante do agrupamento, a realidade do CENTA é muito diferente da escolar. A escola rege-se por lógicas e ritmos muito particulares, onde existem hierarquias que se devem respeitar, sendo o CENTA uma estrutura independente, habituada a outro tipo de funcionamento. As diferenças na dinâmica das duas estruturas organizacionais poderão ter contribuído para as dificuldades de articulação.

Paralelamente, foram apontados outros aspectos que dificultam o sucesso integral do projecto. Os professores chamam a atenção para as difíceis condições de trabalho em que laboram, especialmente quando são consideradas as directrizes do Ministério da Educação que exigem uma gestão rigorosa de todas as horas lectivas e as barreiras geográficas do território que dificultam o trabalho em conjunto do corpo docente do primeiro ciclo.

\section{A equipa e a direcção do CENTA}

Para a equipa do CENTA, os pontos $m$ ais fortes do PFAC encontravam-se situados em diferentes níveis. Os monitores referem as características definidoras e fundadoras do projecto, como o seu carácter contínuo e excepcional, o facto de estar inserido no currículo, o modo como se articula com conteúdos do programa do primeiro ciclo ou a mobilização de recursos humanos especializados para este fim. Salientaram a pertinência do projecto tendo em conta o contexto em que decorre, enfatizaram o modo como se dispunha a colmatar deficiências do ensino normalizado e referiram o impacto real que teria sobre as crianças.

Ainda sobre as valências do PFAC, a direcção do CENTA realçou o processo evolutivo que o projecto viveu, desde a sua concepção até ao ano lectivo em análise. A continuidade permitiu um crescimento positivo ao nível da gestão (atingiu-se uma boa norma na administração de recursos financeiros e humanos); ao nível da relação formal com o Agrupamento (aprovação do projecto em Conselho Pedagógico em dois anos consecutivos); ao nível da relação com a Associação de Pais (que apesar de inicialmente ter um posição oposta, posteriormente assume um papel importante na tentativa de assegurar a continuidade do PFAC em horário escolar) e ao nível da relação com as entidades locais.

Por outro lado, os principais factores que dificultaram o sucesso pleno do projecto foram identificados no enquadram ento local e institucional do projecto.

O concelho de Vila Velha de Ródão encerra alguns aspectos problemáticos para aplicação do PFAC. Nas escolas, as infra-estruturas nem sempre asseguraram as condições ideais para o decorrer das actividades e, ao nível da comunidade, para além das graves deficiências respeitantes ao apoio humano e social para potenciar o desenvolvimento integral das crianças, parece existir um preconceito em relação ao CENTA. Esta postura possivelmente dificultou a comunicação e a percepção da estrutura enquanto um centro cultural aberto ao trabalho com a comunidade.

$\mathrm{Na}$ especificidade do projecto, a equipa do CENTA assistiu, por vezes, a uma postura desinteressada e ausente em relação às actividades pela parte dos professores, que não asseguravam a continuidade dos temas por eles abordados. Sentiram que a Educação Artística era compreendida como uma estratégia essencialmente lúdica e não pedagógica, o que advogava um papel secundário ao projecto na formação das crianças. Desta forma, o projecto parecia ser entendido como uma imposição com consequências ao nível da gestão da monodocência, apesar de existir, precisamente, para colmatar algumas das dificuldades já mencionadas pelos profissionais de ensino.

Ao nível da própria organização do projecto, os monitores apontaram a ausência de directrizes sobre a postura expectável de cada um dos profissionais presentes nas aulas e a pouca disponibilidade para falar da evolução de casos gerais e específicos.

De um ponto de vista mais centrado na entidade de que fazem parte, os monitores chamaram 
a atenção para a redução de recursos humanos na coordenação do projecto, a acumulação de outras funções no CENTA, bem como a existência de conflitos entre a direcção do CENTA e a direcção do Agrupamento.

Por outro lado, a articulação entre as duas entidades envolvidas na realização do PFAC poderá ter sido complexificada pelas recentes directrizes do Ministério da Educação; pelas difíceis condições de trabalho vividas pelos professores do primeiro ciclo; pelas disposições em ocionais dos professores (saturação, frustração) e pelas particularidades do território, que se revela desvitalizado, carenciado e muito heterogéneo.

A análise crítica da direcção do Centro centra-se, como seria de esperar, nos aspectos mais institucionais do projecto. Segundo este ponto de vista, a relação formal entre o Agrupam ento de Escolas e o CENTA sofreu um recuo considerável, especialmente tendo em conta as últimas acções do Presidente do Executivo (impedimento das actividades de recolha de dados para a avaliação do projecto) e do Corpo de Docentes do primeiro ciclo (apresentação da avaliação final do PFAC directam ente ao executivo). Estas acções que, para a directora do CENTA, surgem sem aviso, parecem ser fruto de uma interpretação divergente sobre o PFAC. A direcção do CENTA concebe os professores como os principais interlocutores do projecto, sendo imperativo, a nível formal, garantir a proximidade em relação a este grupo. A tónica no corpo docente também ocorre neste discurso aquando da identificação de factores negativos para o projecto. A postura desinteressada dos professores é indicada como a dimensão que mais explica as dificuldades de articulação verificadas ao longo do ano.

Considerando o conjunto destes depoimentos, destacamos duas ideias principais. Por um lado, a existência de discursos divergentes entre as entidades envolvidas e, pelo outro, a presença de uma preocupação comum.

O Projecto de Formação Artística Contínua não é percepcionado da mesma forma entre o CENTA e - Agrupamento de Escolas, especialmente na sua dimensão mais formal. Este cenário parece resultar em grandes dificuldades de articulação entre os profissionais envolvidos, algo que consiste mesmo numa preocupação generalizada a todos os intervenientes. De notar que as acções de monitorização planificadas, que são criticadas pelo presidente do conselho executivo, não foram cumpridas pelo próprio corpo de docentes.

Para além de percepções divergentes sobre o projecto, parecem também intervir algumas contrariedades ao nível da definição do plano de trabalho do projecto e de mobilização de recursos humanos necessários para uma coordenação mais plena. São mencionados ainda outros factores não específicos ao PFAC que dificultam o sucesso desta colaboração, nomeadamente as exigentes condições de trabalho com que os docentes actualmente se confrontam e algumas particularidades do contexto local.

Apesar de tudo, não podemos deixar de salientar que os agentes das duas entidades mencionam - papel das actividades no desenvolvimento das crianças e alertam para a necessidade de uma colaboração mais próxima e profícua para o projecto. Subjacente a estes depoimentos notamos uma consciência crítica, embora ambígua, tanto sobre as dificuldades como sobre o valor do Projecto de Formação Artística Contínua.

Pólo da recepção

Alunos do primeiro ciclo

Através de entrevistas individuais estruturadas tentamos recolher as percepções dos alunos sobre o PFAC. As questões colocadas eram simples e devidamente adaptadas à faixa etária dos nossos inquiridos. Com este instrumento, conseguimos registar que os alunos distinguiam as aulas do projecto das aulas regulares, na medida em que, nas primeiras, sentiam-se mais à vontade, «mexiam-se mais", aprendiam coisas novas, os professores eram diferentes e, principalmente, porque eram mais divertidas.

Ainda a este nível, quisemos verificar se os alunos tinham alguma noção da utilidade do projecto, mais especificamente se sentiam que as aulas do PFAC os ajudavam a aprender. As respostas registadas foram amplamente positivas, mas apenas os meninos mais velhos adiantaram explicações: as actividades do projecto auxiliavam a aprendizagem porque aprendiam-se coisas novas, porque brincava-se e aprendia-se ao mesmo tempo e porque deixava os "meninos mais relaxados para fazer melhor os trabalhos da escola".

Para procurar outras evidências destas percepções, recorremos a entrevistas de ex-participantes do projecto que, nessa altura, frequentavam o $5 . \circ \mathrm{e}$ 6. ${ }^{\circ}$ ano de escolaridade. Este grupo guardava uma recordação positiva sobre as actividades e, segundo eles, a intenção do projecto consistia em "brincar $e$ aprender ao mesmo tempo", "desenvolver as crianças", "aprender a fazer as coisas em conjunto".

As aulas das duas áreas artísticas eram claramente distinguidas pelas crianças: $\mathrm{Na}$ Dança os alunos declaram fazer "coisas com o corpo" enquanto que nas aulas de Artes Plásticas referiam o desenvolvimento de "trabalhos com materiais diferentes". De todas as actividades das aulas de dança, os alunos entrevistados preferiram o "jogo de xadrez", a "dança da estrela e do bebé" e a "assinatura gestual". No que concerne às aulas de Artes Plásticas, a aula da "estufa", do "chapéus do pensamentos" e das "casas" foram as mais preferidas. 


\section{Encarregados de Educação}

O Projecto de Formação Artística Contínua é percebido enquanto uma valência positiva para as crianças sendo qualificado de "importante", "enriquecedor", "positivo", "fundamental", "espectacular", "giro" e "útil". Os encarregados de educação salientaram o papel que o PFAC parece ter ao nível do desenvolvimento das crianças através das suas actividades, investindo no seu desenvolvimento global e em competências individuais (como a criatividade e a relação consigo próprios) e sociais (proporcionando situações de grupo que facilitam o estabelecim ento e consolidação de laços). O projecto aparenta ir ao encontro das necessidades da criança, valorizando a sua actividade lúdica e criativa. Nesse sentido, a atitude ou a filosofia do projecto foram apontados enquanto pontos positivos.

Uma outra característica definidora do PFAC é a continuidade. Esta dimensão foi percepcionada pelo grupo entrevistado na Associação de Pais como fundamental e positiva para o projecto, permitindo o seu crescimento e resultados efectivos e visíveis no comportamento das crianças.

No que concerne à esfera das aprendizagens, a articulação com os conteúdos programáticos é indicada como uma mais valia, tal como o facto de possibilitar saberes diferenciados, abrindo novas perspectivas às crianças do prim eiro ciclo. O PFAC, nesta perspectiva, parece contribuir para quebrar a monotonia vivida no contexto de sala de aula. Outros aspectos referidos ao nível das entrevistas dizem respeito à adesão entusiasta por parte dos alunos que consistiu, no ponto de vista dos encarregados de educação, num incentivo às actividades curriculares.

Para além destes aspectos, também a equipa do projecto foi identificada como um elemento positivo na relação pedagógica, pela sua formação especializada e pela relação empática que estabeleceu com as crianças.

Quanto aos aspectos negativos, a ausência de informação sobre o projecto é uma das principais críticas que o grupo de encarregados de educação tem a apontar.

Outro aspecto problemático, mas muito menos consensual, diz respeito à organização horária do projecto. Pelo que percebemos, esta questão já teria sido colocada em anos anteriores e nunca se tinha gerado acordo. Este é o ponto que mais claramente separa a percepção entre o espaço urbano e o espaço rural. Embora ambas as posições estejam presentes nestes dois domínios, o resultado da maioria tende para orientações bem definidas: a maioria dos entrevistados do meio rural defende a mudança do projecto para o período extracurricular; pelo contrário, no meio urbano, a maioria está de acordo com a inserção do projecto em horário cur- ricular. Este tema animou a entrevista com o grupo da Associação de Pais com vários momentos de debate e episódios de discórdia, onde se opuseram os argumentos para a continuidade ou mudança da inserção do PFAC em horário curricular. A articulação foi mencionada como um aspecto fundamental para a inserção do PFAC em horário curricular; na ausência de uma colaboração suficiente, o período extracurricular foi indicado como o mais adequado. $\mathrm{O}$ horário em vigor poderia quebrar o ritmo da aula e o entusiasmo dos alunos pelas actividades prejudicar a continuação das actividades escolares. Como tal, o horário ideal do projecto seria sempre inserido na parte da tarde e, por isso, remetido para o período extracurricular. Em oposição, houve quem alegasse o modo como o projecto fora pensado na sua génese e a importância da inclusão horária das actividades do PFAC para a ideia de monodocência coadjuvada, em defesa do horário em vigor. Outro argumento favorável à continuidade na organização horária do projecto prendia-se com a existência de recursos e técnicas, a usar pelos professores, para minimizar o corte entre a aula e as actividades.

Da parte dos inquiridos do espaço urbano surgiu uma outra inquietação sobre o projecto: a desarticulação entre a Escola e o CENTA. Segundo os encarregados de educação, uma articulação mais evidente permitiria uma adesão mais forte ao projecto, uma abordagem a outros conteúdos curriculares pelos formadores e um maior benefício do projecto, por parte das crianças. A colaboração deficiente entre o CENTA e o Agrupam ento traduz-se, entre outros aspectos, pela incapacidade de detectar problemas precocemente, pela descontinuidade entre as aulas regulares e as actividades do projecto, pela exposição parcial dos trabalhos realizados, pela não adesão ao projecto por parte dos encarregados de educação e pela percepção essencialmente lúdica e não pedagógica das actividades por parte dos professores.

\section{Entidades locais}

Com base nos depoimentos analisados constata-se que a totalidade das entidades locais estaria sensibilizada para a importância de projectos de educação artística envolvendo as crianças. Face às dificuldades educativas presentes, particularmente, nas populações das localidades rurais, este tipo de programas são percebidos como úteis e socialmente relevantes. Por conseguinte, todas as entidades, sem excepção, organizavam esforços e estariam abertas a colaborações para assegurar este tipo de apoio, desafiando a falta de meios e recursos humanos.

Contudo, sobre o PFAC, em particular, existe um grande desconhecimento. O CENTA manteria contactos muito pontuais com as entidades, não explicitando o teor do projecto. Denunciou-se, 
pois, uma falta de divulgação das actividades, realidade considerada especialmente grave no que concerne aos momentos de interacção e abertura à comunidade.

Mesmo sem total conhecimento de causa, os representantes das entidades contactadas reconhecem o valor do PFAC no desenvolvimento das crianças. Defendem que este tipo de projecto estimula as crianças para actividades que "puxam por elas". Por outro lado, é transversal a opinião que todos os investimentos ao nível da educação das crianças são valiosos e contribuem, consequentemente, para o desenvolvimento da freguesia.

No que diz respeito às relações entre a comunidade e o CENTA, os representantes alertam para a existência de um preconceito em relação à estrutura. O CENTA é percebido como uma entidade distante e elitista, com um trabalho pouco relevante para a comunidade. Apesar de se detectar um preconceito por parte da população do concelho de Ródão, este não se repercute ao nível dos representantes das freguesias: existe uma ampla abertura para futuros contactos, ao mesmo tempo que se reconhece o valor da intervenção na comunidade de uma estrutura como o CENTA.

O caso mais excepcional, neste âmbito, refere-se às relações com a Câmara do Município. Os contactos anteriores foram pautados por conflitos com a direcção do CENTA. A presidente da Câmara vê o CENTA como muito distante dos interesses e necessidades reais da comunidade do concelho.

\section{Considerações Finais: Propostas de futuro (com futuro?)}

Na periferia da periferia o CENTA luta com um imaginário e uma memória histórica adversos. $\mathrm{Na}$ verdade, o centro do CENTA é uma grande casa agrícola, a Tapada da Tojeira, símbolo de uma desigual distribuição da propriedade agrícola. Por isso, quando Madalena Vitorino e Graça Passos tomaram em mãos o projecto visavam, antes de tudo, experimentar, despir e vestir, baralhar significados e significantes: "Experimentar o quê? Experimentar no campo da produção cultural, no campo da criação artística, no campo da agricultura" (Passos, 2007:58). Ganha força a ideia, além do mais, de uma contextualidade: "acredita numa relação directa entre os movimentos (estéticos) e os ambientes onde se implantam, ou seja, toma os sítios como lugares estéticos a habitar e, simultaneamente, como fontes de inspiração" (idem: 59).

No entanto, parece claro, à luz do referido em anteriores páginas, que o estatuto da educação artística está longe de se encontrar estabelecido no campo escolar. Aliás, a própria ideia do que é o núcleo-duro do currículo ou, tão-só, do que é currículo continua a ser atravessada por forte conflitualidade interna. A ambivalência atinge, por vezes, o discurso do mesmo interlocutor. A educação artística pode ser valorizada por professores, pais e alunos como elemento facilitador da relação e da interacção sociais mas o seu registo "lúdico" situa-a no exterior dos assuntos "sérios", logo, curriculares. Existe uma espécie de luta simbólica - que não deixa de ser uma luta efectiva pela obtenção de poder - pelo monopólio da definição do conteúdo do currículo. Esta luta e tensão são, a nosso ver, exacerbadas numa situação em que o agrupam ento escolar é um dos poucos recursos do concelho. Dir-se-ia mesmo que a escola e o CENTA são os protagonistas locais. Protagonistas que se encontram e desencontram através do projecto, tornado, inevitavelmente, foco de disputa. É certo que há uma consonância generalizada sobre a relevância e utilidade do projecto, bem como a sua adequação à realidade escolar concreta, mas multiplicam-se referências quanto às descontinuidades que estabelece face aos espaços-tempos «normais», isto é, realmente curriculares. Ora, a potenciação dos objectivos do projecto só alcançará os seus desideratos com uma plena integração curricular e inserida no modelo da docência coadjuvada e do trabalho em equipa entre professores de valências diferentes. Falou-se, por isso, de desarticulação temporal entre os conteúdos das aulas e actividades, apesar de tanto os monitores e os professores realçarem quão fundamental era o projecto, ainda que estes últimos pouco se envolvessem, dada a percepção de que o processo era, no essencial, exterior à actividade docente. Faltou, pois, monitorização e multiplicação de momentos de articulação e planeamento conjuntos, os quais permitiriam corrigir passos desajustados (função reabilitadora) e evitar a reprodução de opções erradas (função preventiva), ao mesmo tempo que criariam, porventura, um sentimento e representação de afinidade entre docentes e monitores (função de integração e coesão).

No entanto, o actual «mal-estar» docente pode reflectir-se de várias formas e algumas delas não potenciam a integração curricular da educação artística. Sobre a escola tudo pesa, novas exigências, acrescidas responsabilidades. A crise da escola (o abandono e o insucesso, a alegada falta de "qualidade" dos processos de aprendizagem, as novas modalidades de selecção social) são geralmente resolvidas...com mais escola e mais da mesma escola! Ora, o PFAC imagina uma outra escola, a partir das entranhas da que existe. Mas não possui recursos humanos, técnicos e financeiros suficientes para suplantar debilidades estruturais (origens sociais de alunos e famílias, contexto demográfico e sócio-territorial, escassa mobilização para os investimentos simbólicos...). A periferia da periferia exigiria mais formadores, com um plano de trabalho e uma estabilidade contratual pelo menos 
correspondente aos quatros anos do primeiro ciclo e, simultaneam ente, autarquias atentas e em sinergia, professores mobilizados e não «desterrados», escolas bem equipadas.

Impõe-se, por isso, um real funcionamento em rede. Mas para que exista rede necessitamos de pontos ou lugares na rede. E muitos dos agentes locais demitiram-se, até ao momento, de o serem. O que requer, por parte do CENTA, um maior esforço de mobilização da população e desenvolvimento, na sua equipa técnica, de competências de mediação sócio-cultural capazes de criarem, por exemplo, dispositivos de informação que permitam um real acesso das populações escolares e das famílias em geral às ofertas do projecto. O real acesso significa, por exemplo, a produção de conteúdos efectivamente decifráveis pelas populações em causa, condição indispensável para a sua incorporação.

Não nos esqueçamos, no entanto, que o mais importante do PFAC está por avaliar. Na realidade, importa aquilatar um processo completo com a duração de quatro anos ( 1 ciclo do Ensino básico). É certo que nos foi já possível detectar, com alguma prudência, um conjunto de aparentes mudanças nas disposições estéticas e relacionais dos alunos que participaram no projecto, em comparação com um grupo de discentes que não teve qualquer contacto com a educação artística curricular. Mas a mudança nas disposições requer durabilidade, sistematicidade e forte envolvimento. Não nos esqueçamos que, para muitas destas crianças e suas famílias, não existe uma ideia de projecto escolar. Frequentemente permanece-se na escola por ausência de outras alternativas (não se trata, na verdade, de um concelho marcado pela utilização intensiva de mão-de-obra infantil e juvenil porque na periferia da periferia praticamente não existe actividade industrial). Além do mais, a incorporação de disposições estéticas por parte destas crianças tem de caminhar a par com a inculcação por parte dos pais e outros agentes locais da importância de tal processo. Importa perceber que, para se ganharem as crianças, famílias e autarcas têm de ser conquistados. Caso contrário, mesmo que a articulação escola/CENTA funcione na perfeição, ainda não será suficiente, porque na periferia da periferia não haverá, fora da escola, contextos de mobilização nem consolidação das competências estéticas, corporais, relacionais que rapidam ente cairão na inibição e esquecimento que as desactivará.

Assim, não deixa de ser relevante que um dos resultados desta avaliação seja, precisamente, a continuação do processo, instaurado, doravante, em modalidade de Observatório. É que nada saberemos de nós próprios se não formos capazes de perceber as possibilidades de mudança na periferia da periferia.

\section{Referências bibliográficas}

ABREU, Manuel Amâncio Viegas (2002), Cinco Ensaios Sobre Motivação, Coimbra, Livraria Almedina.

BOGDAN, Robert e S. Bilken (1994), Investigação Qualitativa em Educação. Uma introdução à teoria e aos métodos, Porto, Porto Editora.

CAPUCHA, Luís, J. F. Almeida, P. Pedroso e J. A. Vieira Silva (1996), "Metodologias de avaliação: o estado da arte em Portugal", Sociologia - Problemas e Práticas, 22, pp. 9-27.

CNEA (Comissão Nacional para a Educação Artística) (2004), Roteiro para a Educação Artística, Lisboa, CNEA.

FIGARI, Gérard (1996), Avaliar: Que referencial?, Porto, Porto Editora.

GARDNER, Howard (1994), Educatión artística y Desarrollo Humano, Barcelona, Ediciones Paidos.

IIC (Instituto de Inovação Curricular) (s/d), Projecto Promoção da Educação Inclusiva. Vertente Investigação - Acção,

$<$ www.dgidc.minedu.pt/inovbasic/proj/inclusivas/ vertenteinv_accao.htm >

PASSOS, Graça (2007), "CENTA. Um espaço improvável no meio dos campos", OBS, Lisboa, Observatório das Actividades Culturais.

PINTO, José Madureira (2002), "Factores de sucesso/ /insucesso", in CNE, Sucesso e Insucesso no Ensino Superior Português, Lisboa, Conselho Nacional da Educação.

PAIS, José Machado (1982), "Usos do tempo e espaços de lazer", in A juventude Portuguesa: situações, problemas, aspirações, Lisboa, Instituto de Ciências Sociais.

SOUSA, Alberto B. (2003), Educação pela Arte e Artes na Educação (vol.1), Lisboa, Instituto Piaget.

STOER, Stephen R.; Luíza Cortesão e José A. Correia (2001), Transnacionalização da educação. Da crise da Educação à "Educação da Crise", Porto, Edições Afrontamento.

VILHENA, Teresa (2000), Avaliar o Extracurricular: a referencialização como nova prática de avaliação, Porto, Edições Asa.

WEBER, Anita (2004), "Saberes sociais e saberes escolares. Para uma problemática articulação" in E. Leite et al., Trabalho de Projecto 2. Leituras comentadas, Porto, Edições Afrontamento. 